\title{
Research on the Optimal Scheme and the Effect of Tunnel Construction of the Existing line on the Railway Station
}

\author{
Zhuangfei Yin ${ }^{1, a}$ \\ ${ }^{1}$ School of Transportation Engineering, Shandong Jianzhu University, Jinan, 250101, China \\ ª21643578@qq.com
}

Keywords: Existing railway line; Tunnel; Station; Safety; Optimal scheme.

Abstract.Aiming at the safety problem during the tunnel construction of the existing railway at the Hechuan Station, generalize the analysis model, using the method that combined the MIDAS/GTS with the numerical simulation procedure GDEM, the effect of the tunnel construction on the Hechuan station is research. The superiority of different schemes that the pile-back beam and continuous wall is researched. On this basis, the superiority of different schemes are concluded, and then the optimal scheme is proposed that the rib type plate, which can protect the safety of the station and the existing railway line.

\section{Introduction}

At present, the development of the construction in high-speed railway and expressway is fast in China. Due to the curve radius of the high speed rail line are large, there are inevitably grade separations of tunnels especially around the hilly city[1-6]. The new highway tunnels have a major influence to the existing railway and the buildings around. And the security of station building is threatened when the new tunnel is constructed near it. So it is very necessary to study the influence to the station security of the new tunnel construction.

\section{Engineering general situation}

Under the existing railway in the Hechuan station of Chengdu-Chongqing Railway, there is a tunnel which is constructed by the way of box-culvert advancing in the vertical direction. And the size of box culvert (length $\times$ width $\times$ height) is $40 \mathrm{~m} \times 14 \mathrm{~m} \times 10 \mathrm{~m}$ with the thickness of $1.8 \mathrm{~m}$. The bed plate with the ribbed beams of the box culvert is made by cast-in-place concrete. The thickness of the bed plate is $0.3 \mathrm{~m}$. And the space between ribbed beams is $6 \mathrm{~m}$, which the height and width of the ribbed beam are $1.0 \mathrm{~m}$ and $6.0 \mathrm{~m}$. There is a back beam set behind the box culvert which the sectional dimension (length $\times$ width $\times$ height) is $12.0 \mathrm{~m} \times 1.2 \mathrm{~m} \times 1.2 \mathrm{~m}$. About $5 \mathrm{~m}$ from the back beam, two piles of the Hechuan station foundation are located, which a $16.0 \mathrm{~m}$ length connect thin beam is set with the sectional dimension of $1.0 \mathrm{~m} \times 0.3 \mathrm{~m}$. And the constructions above are depicted in the Fig. 1 . For the synchronization of the advancing process, there are four jacks set behind the back beam uniformly, which the force of every jack is $2500 \mathrm{kN}$. And for the security of the advancing, under boards are set between the jacks and the box culvert. Based on the above situations, it is the key to keep the security of the piles and the connect beam during the advancing process.
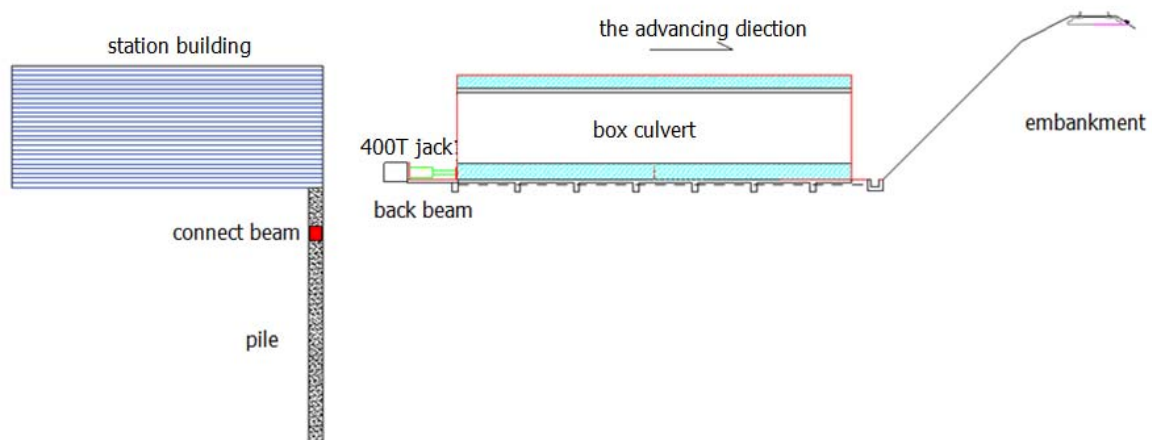

Fig.1 The front view of each part 


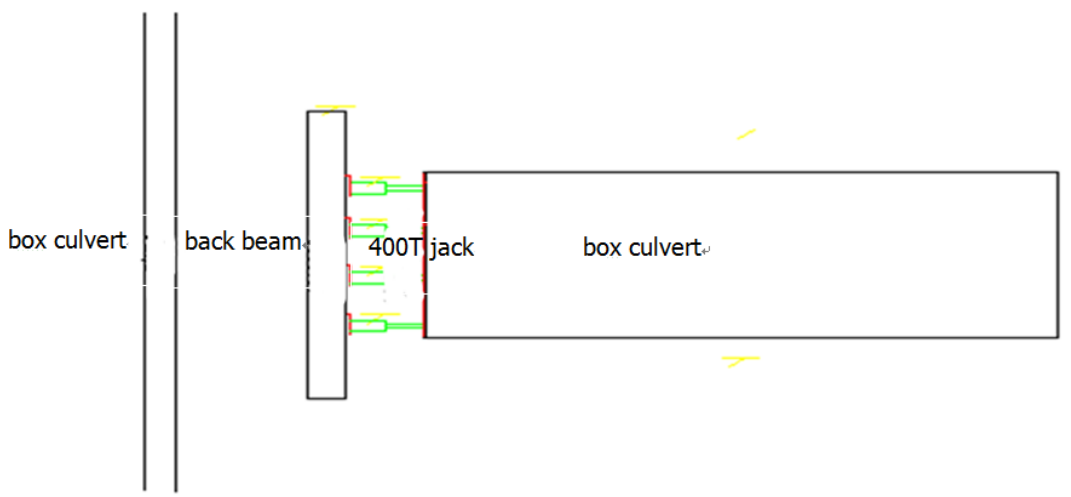

Fig. 2 The plan form of each part

For keeping the security of the connect beam in the process of advancing, two kinds of the solutions are proposed as follows. The (1) is that setting the manual hole digging pile with coping made by M10 mortar flag stones behind the connect beam, which is acting as counterforce device in the advancing process. The buried depth of the manual hole digging pile is $6 \mathrm{~m}$. And the top and bottom width of the coping are $2.0 \mathrm{~m}$ and $4.0 \mathrm{~m}$, which is with $12.0 \mathrm{~m}$ length and $5.0 \mathrm{~m}$ height. The (2) is to put the underground diaphragm wall and the coping as the counterforce device behind the connect beam, which the buried depth of the underground diaphragm wall is $6.0 \mathrm{~m}$, and the dimensions of the coping are the same as the above. It's worth noting that the base plate is not connected with the underground diaphragm wall or the manual hole digging pile.

\section{Numerical Analysis}

The analytical model is generalized based on the engineering general situation above, which is depicted in the Fig. 3 and Fig. 4. In the analytical models of both Plan 1 and 2, solid elements are applied to simulate the continuous walls, pile foundations, M10 mortar flag stones, back beam, manual hole digging piles, connect beam, bed plate and the filling. So the stress conditions of each part above can be simulated more really in the advancing process. For simulating the interaction between the soil and structures, interface elements are set on the surfaces of models of the pile foundation, M10 mortar flag stones, back beam, manual hole digging piles, connect beam. For eliminate the boundary effect, the boundary dimensions are $50 \mathrm{~m} * 25 \mathrm{~m} * 20 \mathrm{~m}$. Due to the difference of the Plan 1 and 2 is selecting manual hole digging pile or underground diaphragm wall, only the model of the Plan 1 is depicted in this paper.

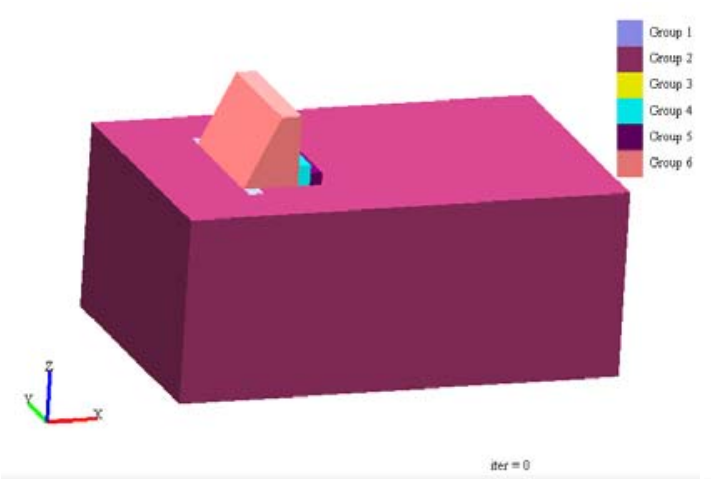

Fig.3 The model of Plan 1
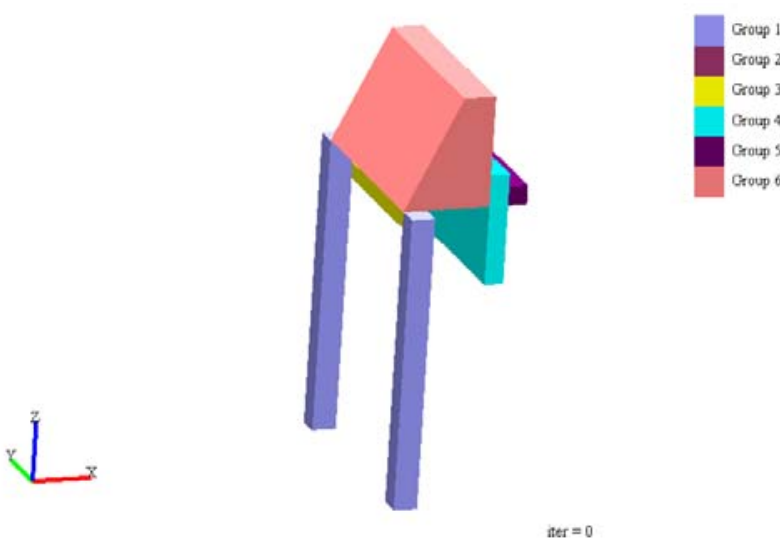

Fig. 4 The model of some components in Plan 1

\section{(1)The procedure of numerical calculation.}

For estimate the security of the connect beam in the advancing process more really, three kinds of the numerical analysis programs are applied in this paper, MIDAS/GTS, FLAC3D and GDEM. And these are combined by the conversion programs between each other. The preprocess treatments are 
made by MIDAS/GTS. After model transformation made by FLAC3D, GDEM is applied to the post processing treatment. And making full use of the advantages of each procedure, we can get the results more and more accurately. The conversion programs between different procedures are showed in the Fig.5 and Fig. 6.

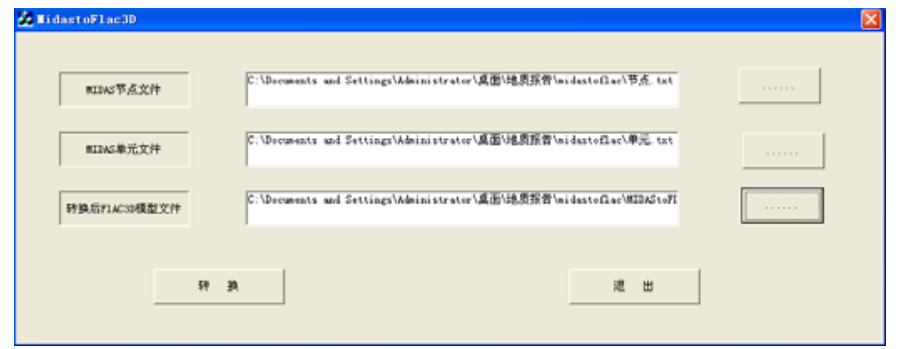

Fig.5 The conversion program between MIDAS/GTS and FLAC3D

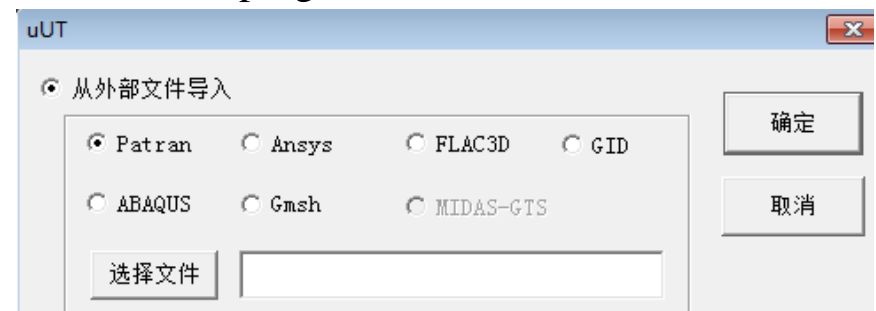

Fig. 6 The conversion program between FLAC3D and GDEM

\section{(2)Constitutive model and Material parameters.}

There are three kinds of external load in this numerical analysis, the gravity of box culvert, the advancing force, and the dead load of superstructure applying to the pile foundation. The gravity of the box culvert is $1100 \mathrm{~m} 3 \times 26 \mathrm{kN} / \mathrm{m} 3=28600 \mathrm{kN}$, and the compression area is $10 \mathrm{~m} * 50 \mathrm{~m}=500 \mathrm{~m} 2$, so the intensity of pressure is $57.2 \mathrm{kpa}$. The whole advancing force is $10000 \mathrm{kN}$, which the force provided be each jack is $2500 \mathrm{kN}$. Due to the load above the pile foundation influences the results little, so this load is estimated $20000 \mathrm{kN}$ without calculation accurately. Furthermore, the failure criterion of the soil is More-Kulun criterion, and the linear elasticity constitutive model is applied in the models of connect beam, pile foundation, back beam and bed plate. For simulating the interaction between the soil and structures, the More-Kulun criterion and the brittle fracture constitutive model are used in the elements of the connect surfaces. The material parameters applied in the numerical analysis are depicted in the Table. 1.

Table. 1 The list of parameters

\begin{tabular}{|c|c|c|c|c|c|}
\hline & $\begin{array}{c}\text { volume-weight } \\
{[\mathrm{kN} / \mathrm{m} 3]}\end{array}$ & $\begin{array}{c}\text { elasticity } \\
\text { modulus } \\
{[\mathrm{kPa}]}\end{array}$ & $\begin{array}{c}\text { Poisson's } \\
\text { ratio }\end{array}$ & $\begin{array}{c}\text { cohesion } \\
{[\mathrm{kPa}]}\end{array}$ & $\begin{array}{c}\text { internal } \\
\text { friction } \\
\text { angle } \\
{\left[{ }^{\circ}\right]}\end{array}$ \\
\hline $\begin{array}{c}\text { unreinforced } \\
\text { filling }\end{array}$ & 19.5 & 35 & 0.31 & 22 & 20 \\
\hline pile foundation & 25.0 & $2.0 \mathrm{e} 7$ & 0.22 & $/$ & $/$ \\
\hline connect beam & 25.0 & $2.0 \mathrm{e} 7$ & 0.22 & $/$ & $/$ \\
\hline $\begin{array}{c}\text { M10 mortar flag } \\
\text { stone coping }\end{array}$ & 23.6 & $2.0 \mathrm{e} 5$ & 0.23 & $/$ & $/$ \\
\hline $\begin{array}{c}\text { manual hole } \\
\text { digging pile }\end{array}$ & 25.0 & $2.0 \mathrm{e} 7$ & 0.22 & $/$ & $/$ \\
\hline back beam & 25.0 & $2.0 \mathrm{e} 7$ & 0.22 & $/$ & $/$ \\
\hline bed plate & 25.0 & $2.0 \mathrm{e} 7$ & 0.22 & $/$ & $/$ \\
\hline
\end{tabular}




\section{(3) Analysis of calculating result.}

According to the results of the numerical analysis, the displacement and stress field, and the distribution of plastic strain are selected to analyze, which are showed in the figures from Fig.7 to Fig. 12. The key emphasis in this paper is to analyze the security of the connect beam between the piles in the advancing process. So in the figures from Fig. 7 to Fig. 10, only the displacement and stress field of the connect beam are depicted.

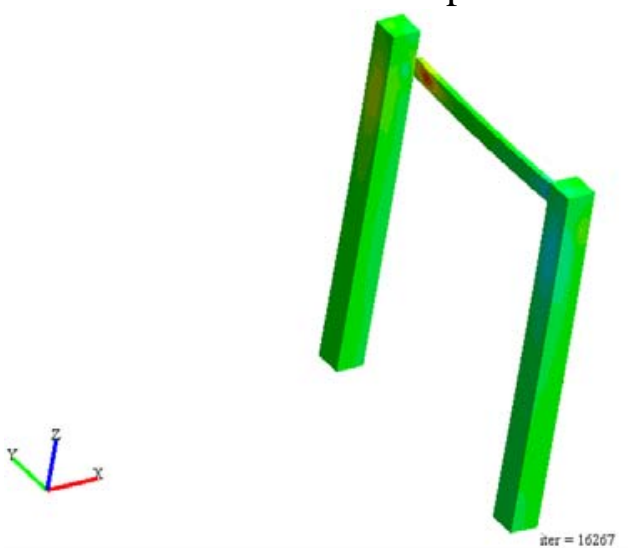

Fig. 7 the stress field of connect beam in Plan 1

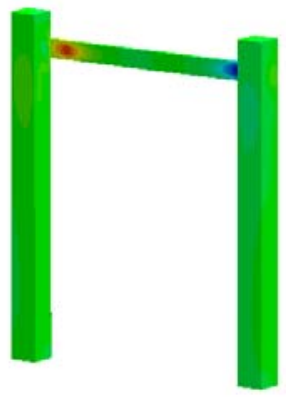

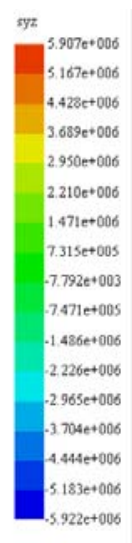

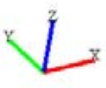

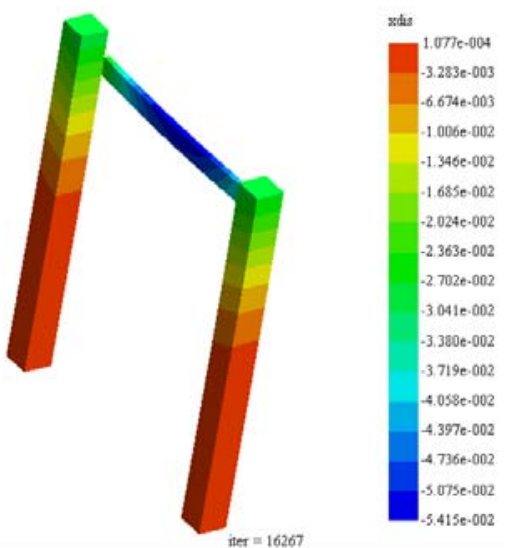

Fig. 8 the displacement field of connect beam in Plan 1
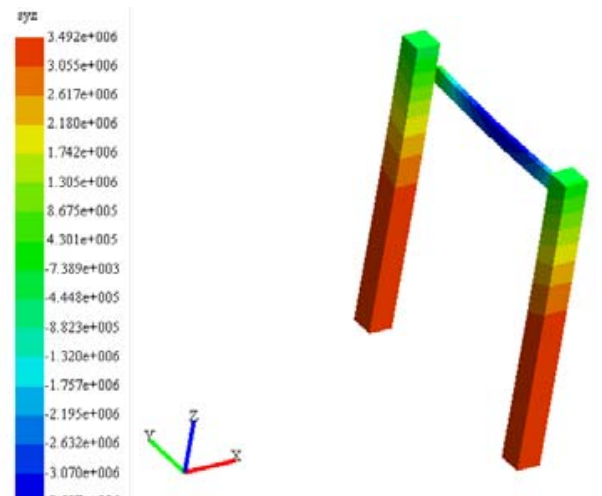

inter $=17333$

Fig. 9 the stress field of connect beam

Fig. 10 the displacement field of connect beam in Plan 2

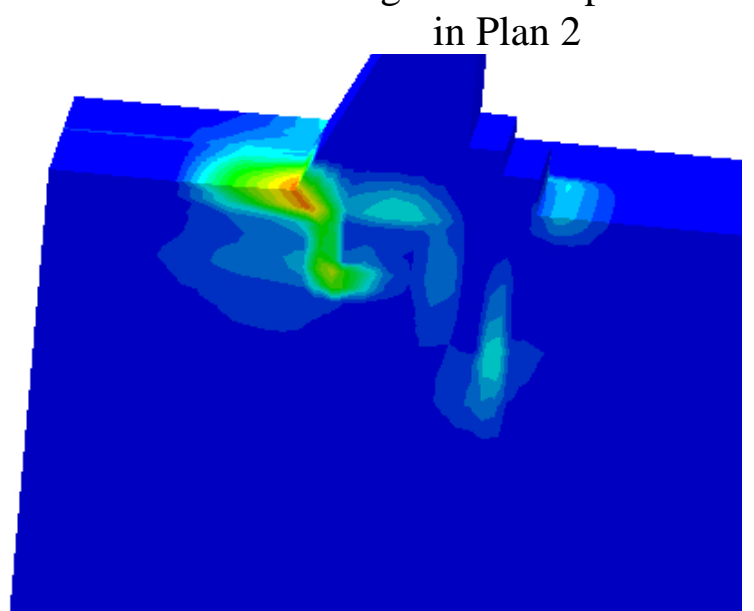

Fig. 11 the distribution of the plastic zone in Plan 1 


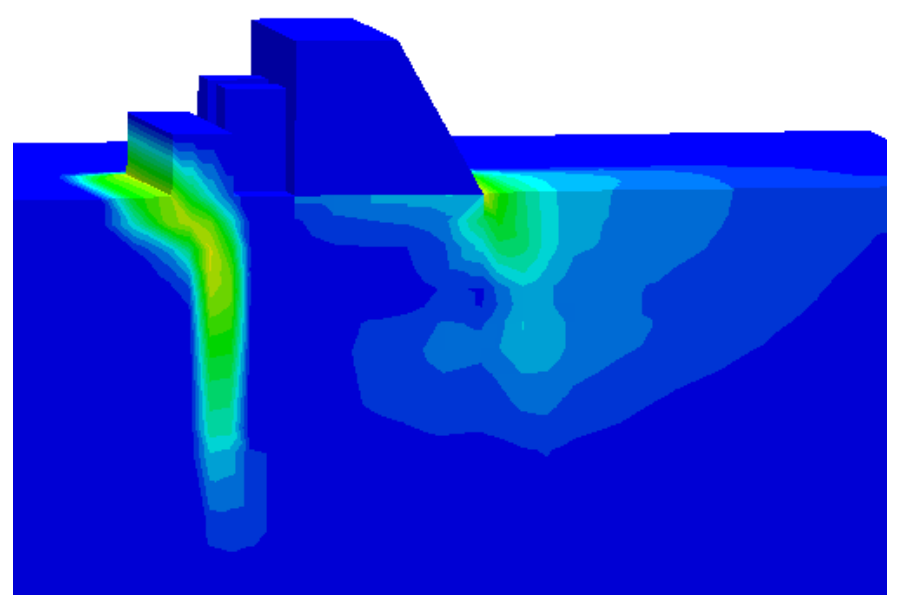

Fig. 12 the distribution of the plastic zone in Plan 2

Analyzing the figures from Fig. 7 to Fig. 10 comprehensively, the largest tensile stress of the connect beam in Plan 1 is $5.907 \mathrm{MPa}$, which the largest deflection is $5.415 \mathrm{~cm}$. However, the maximum allowable tensile stress of the connect beam is $3.86 \mathrm{MPa}$ according to the calculation results of the bearing capacity. To the Plan 2, the largest tensile stress is 3.492MPa where the maximum deflection is $2.77 \mathrm{~cm}$. Though the calculation results of Plan 2 meet the allowable tensile stress of the connect beam, the safety stock is small. Furthermore, the plastic zone develops to the bottom of the piles, and focuses on the connect beam in Fig.11. And a lot of plastic zone concentrates in the continuous wall, and little in the connect beam.

According to the analysis above, the Plan 1 is not safe. Though the Plan 2 can meet the security of the connect beam, the safety stock is small. Due to the construction site is complex with more influence factors, both Plan 1 and Plan 2 are not applied.

\section{(4) The optimal case.}

Based on the calculation results of the Plan 1 and Plan 2 above, the system can't offer enough resistance in the advancing process, and the deflection of the connect beam is too large. So the Plan 3 is put forward as follows. Set the manual hole digging piles and the coping made by M10 mortar flag stones as the reaction system behind the connect beam, which the buried depth of the manual hole digging piles is $4.0 \mathrm{~m}$, and the top and bottom width of the coping is $2.0 \mathrm{~m}$ and $3.0 \mathrm{~m}$ with $2.0 \mathrm{~m}$ height and $12.0 \mathrm{~m}$ length. Furthermore, the bed plate is connected with the manual hole digging piles to make full use of the soil resistance under the bed plate. According to the plan above, the model is established depicted in the figures from Fig. 13 to Fig. 16, which the parameters are the same as above.

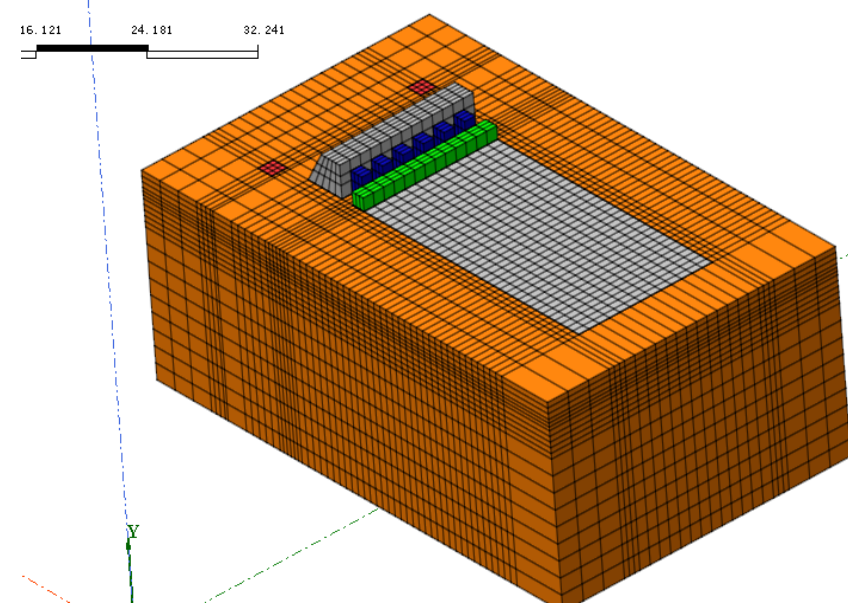

Fig. 13 The whole model of Plan 3

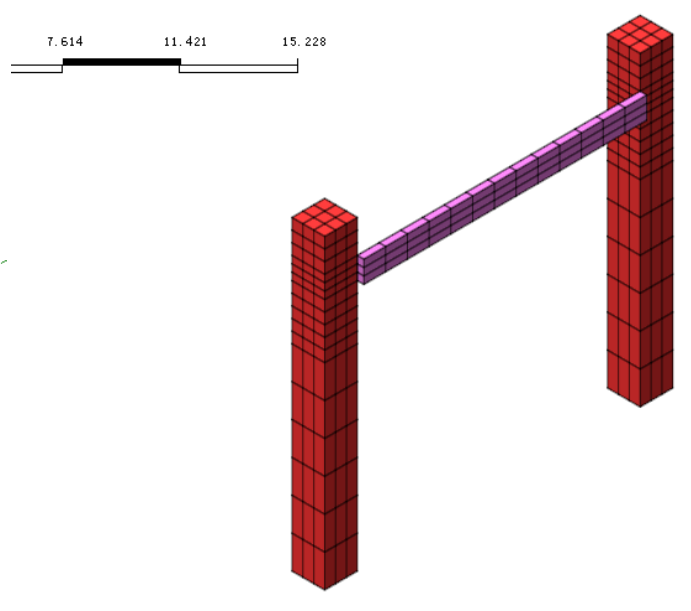

Fig. 14 The model of connect beam in Plan 3 

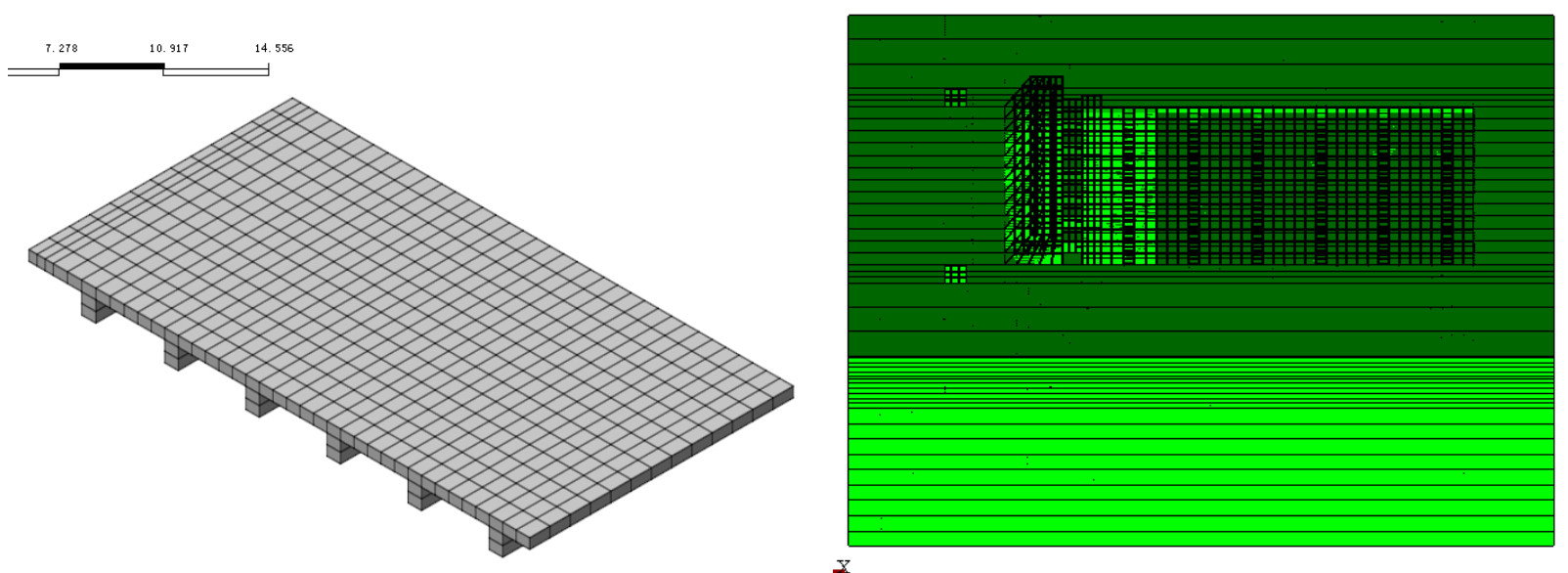

Fig .15 The model of bed plate in Plan 3 Fig.16 The model of the interface elements in Plan 3

\section{(1) The analysis of the calculation results for the optimal case}

According to the results of the numerical analysis, the displacement and stress field, and the distribution of plastic strain are selected to analyze, which are showed in the figures from Fig.17 to Fig. 20.。

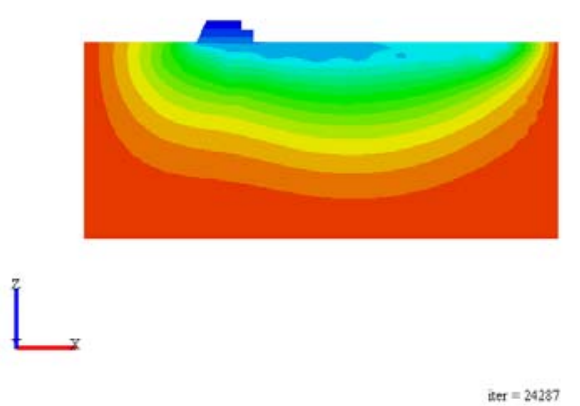

Fig. 17 The displacement field of the whole model in Plan 3

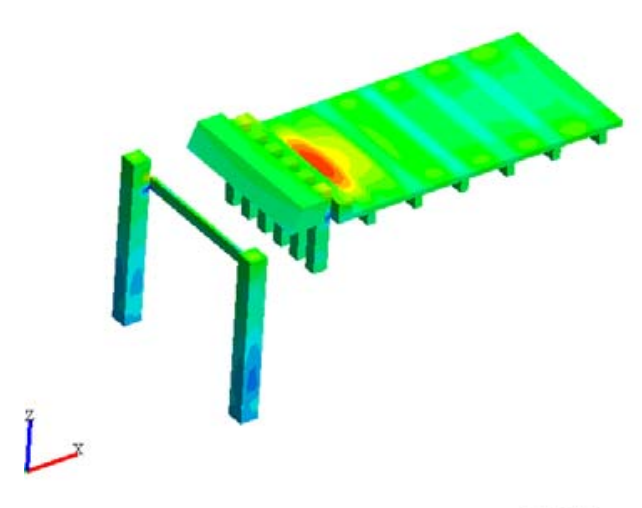

iter $=27971$

Fig. 19 The stress cloud chart of components in Plan 3

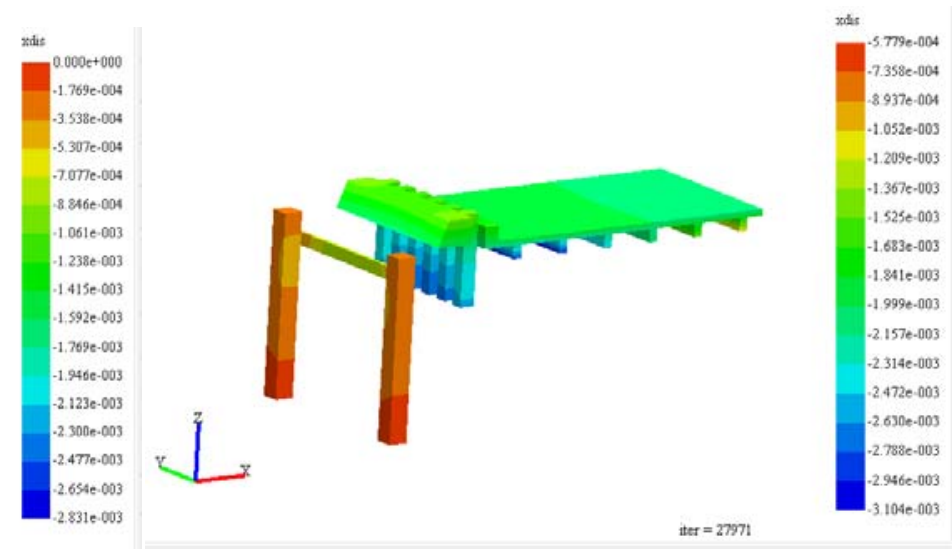

Fig. 18 The displacement cloud chart of components in Plan 3

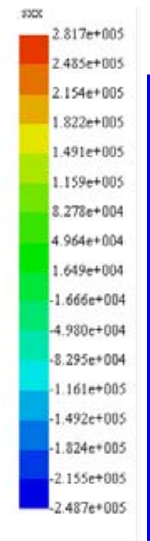

Fig. 20 The distribution of the plastic zone in Plan 3

Comprehensively analyzing the figures from Fig. 17 to Fig. 20, the largest tensile stress of the connect beam in Plan 1 is $1.33 \mathrm{MPa}$ which is smaller than the tensile strength of the bed plate. And the stress concentration area distributes the connection zone between the manual hole digging piles and the bed plate, which should be reinforced locally. And for the connect beam, the tensile stress is about $1.331 \mathrm{MPa}$ which is much smaller than the tensile strength, and situation of the manual hole digging pile is the same. In addition, the maximum deformation of the connect beam and manual hole digging 
pile are $1.56 \mathrm{~mm}$ and $1.82 \mathrm{~mm}$, which is smaller than the limiting value. And the plastic zones in the model are small and connected with each other. On the whole, applying the Plan 3 can keep the whole system safe in the advancing process.

\section{Conclusion}

Aiming to the safety issue in the construction process of the tunnel under Hechuan station belong to the existing Chengdu-Chongqing railway, the advantages and the disadvantages of three plans are demonstrated in this article according to the results of the numerical analysis. The optimum one is determined, and some conclusions are obtained as follows.

(1)When designing the plan of the box-culvert advancing, the influences to the around constructions should be taken a full consideration. And for keeping the safety of the reaction wall and the structures behind it, make full use of the interaction force between the soil and the bed plate to enhance the resistance.

(2)According to the results of the analysis, the Plan 3 is determined which can keep the safety in the advancing process with the improved structure and lower cost, which is described as follow. Set the manual hole digging piles and the coping made by M10 mortar flag stones as the reaction system behind the connect beam, which the buried depth of the manual hole digging piles is $4.0 \mathrm{~m}$, and the top and bottom width of the coping is $2.0 \mathrm{~m}$ and $3.0 \mathrm{~m}$ with $2.0 \mathrm{~m}$ height and $12.0 \mathrm{~m}$ length. When calculating the reinforcement, it's worth to note that the issue of the stress concentration in the connection between the manual hole digging pile and the bed plate.

(3)In the advancing process, the reaction wall made by the continuous wall, back beam and coping is better than it made by the manual hole digging pile, back beam and coping, and the latter one can't meet the security requirement.

(4)When making numerical calculations, the advantages of each analysis software can be made full use to make the calculation results more accurately.

\section{References}

[1] Economic planning institute of the ministry of railways. TZ202-2008 Mixed passenger guide line railway roadbed construction technology [S]. Beijing: China Railway Publishing House, 2008

[2] XU Gan-cheng, LI Cheng-xue, WANG Hou-yu, ZHAO Yue, HU Ping. Analysis of influence of metro shield tunneling crossing underneath high speed railway [J]. Rock and Soil Mechanics, 2009, 30(S2): 269

[3] WANG Qing-guo SUN Yu-yong. Numerical Analysis of Settlement for a Shield Tunnel Under-passing the Existing Railway with Rotary Jet Pile [J]. Chinese Journal of Underground Space and Engineering, 2008，4(5): 861

[4] Wang Yulong. Study on Mechanics Feasibility and Counter Measure of Tri-tunnels Undergo Railway Caused by Train Vibration [D]. Chengdu: Southwest Jiaotong University, 2012

[5] LÜ Peilin, ZHOU Shunhua. Analysis on Upper Rail Settlement in Soft Ground Resulting from Shield Tunnelling across Main Railway Line [J]. China Railway Science, 2007, 28( 2) : 12

[6] BIAN Jin , TAO Lian-jin , GUO Jun. The Ground Settlement Monitoring of a Shield Tunnel [J]. Chinese Journal of Underground Space and Engineering, 2005, 1( 2) : 24 